Andrea Moneta

Output Number 3: Gandhi King Ikeda - Peacebuilders Exhibition Nottingham Trent University and Broadway Cinema Gallery, May 2017

Portfolio part 1: Documentation of Work 
The output 3 illustrates the development of the design process and realisation of the GKI Peacebuilders exhibition in two different venues in Nottingham, following a humanistic approach based on true Dialogues with the visitors. Included, are also supplementary materials to demonstrate significance and originality of the research outputs.

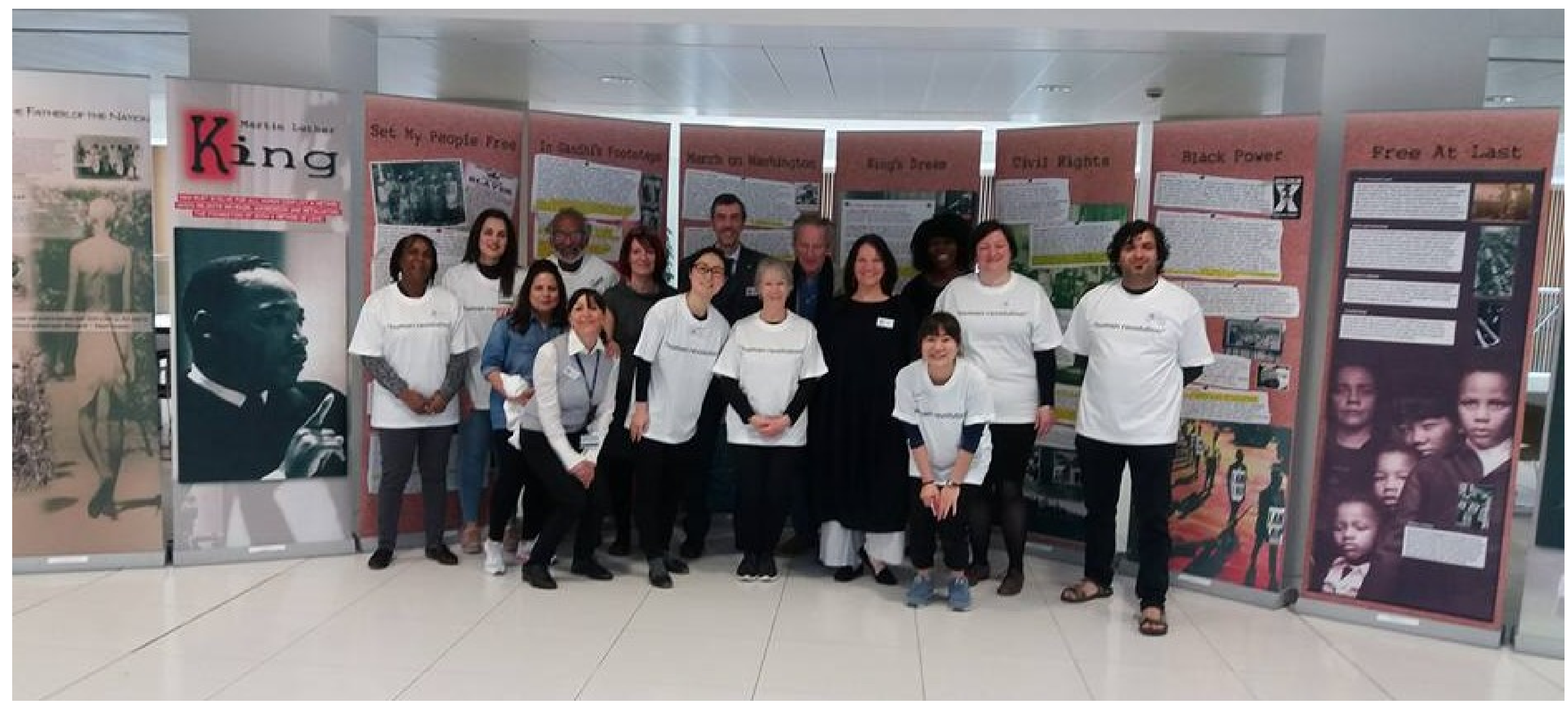


GKI Exhibition in Newton Building - Forum Level 1 Nottingham Trent University, 2-5 May 2017 
The exhibition has been enabled and funded by SGI-UK;

The organisation lasted 5 months and involved 54 SGI

volunteers of four Nottingham Districts, two Leicester

Districts, two Lincoln Districts and two Derby Districts;

Inspirational quote and Design of GKI Exhibition in Newton Building Forum Level 1, Nottingham Trent University, 2-5 May 2017

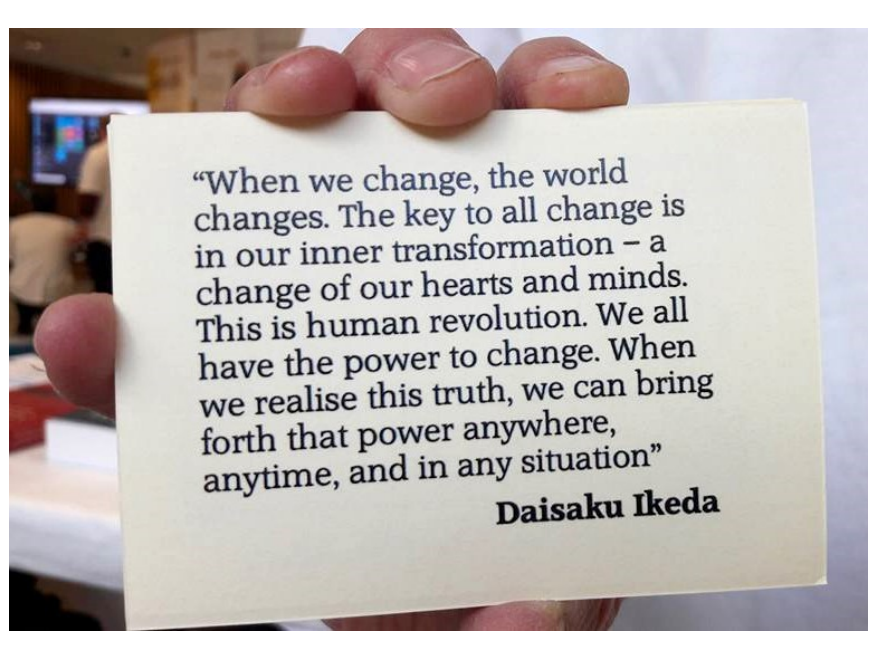

"When we chang

anywhere,

Daisaku Ikeda
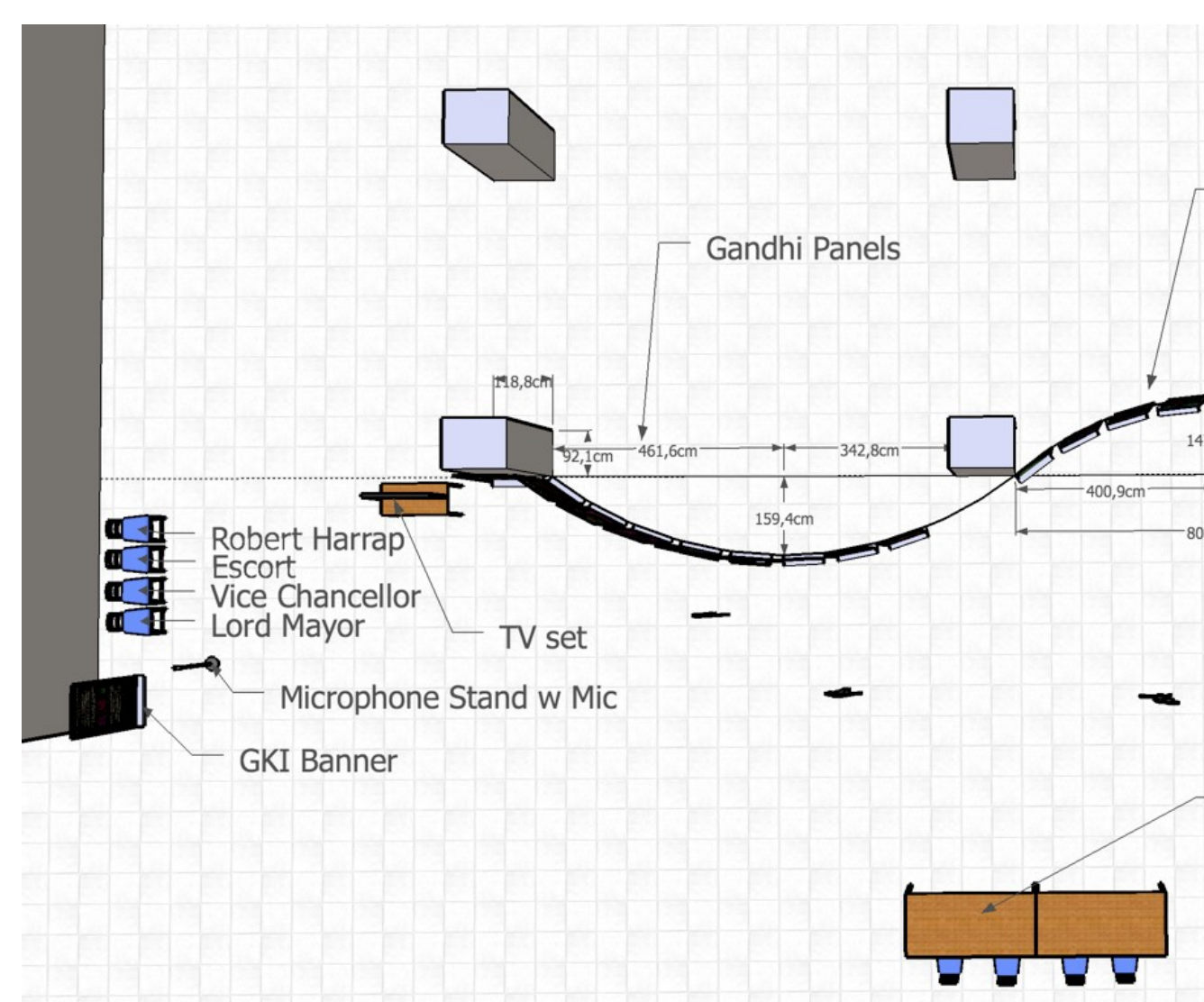

King Panels
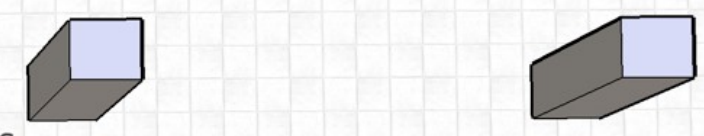

Ikeda Panels

Info, leaflets, etc

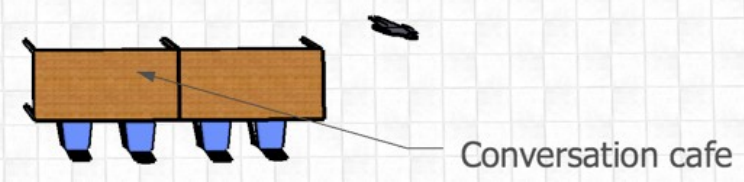



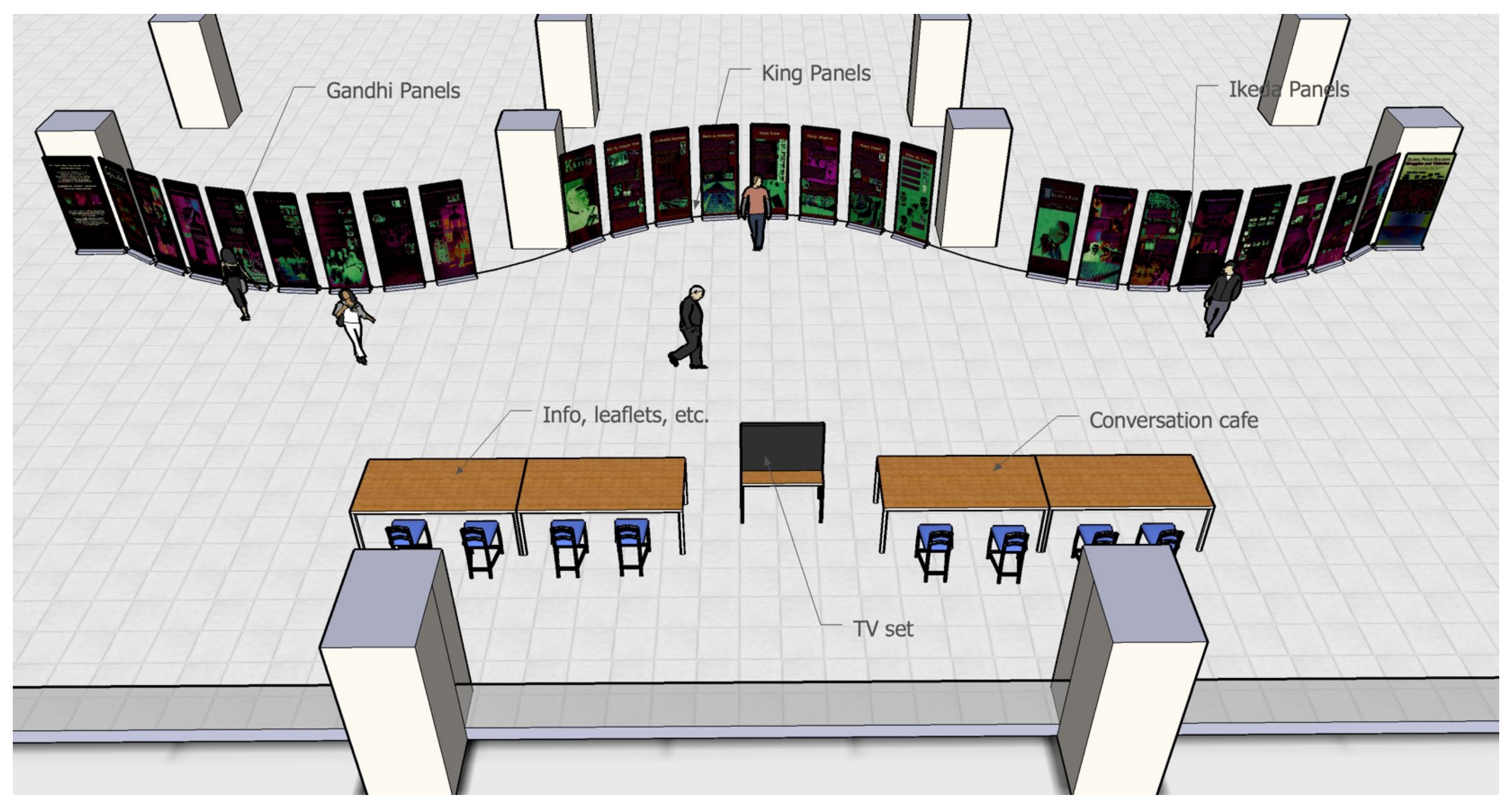

Design of GKI Exhibition in Newton Building Forum Level 1 Nottingham Trent University, 2-5 May 2017 


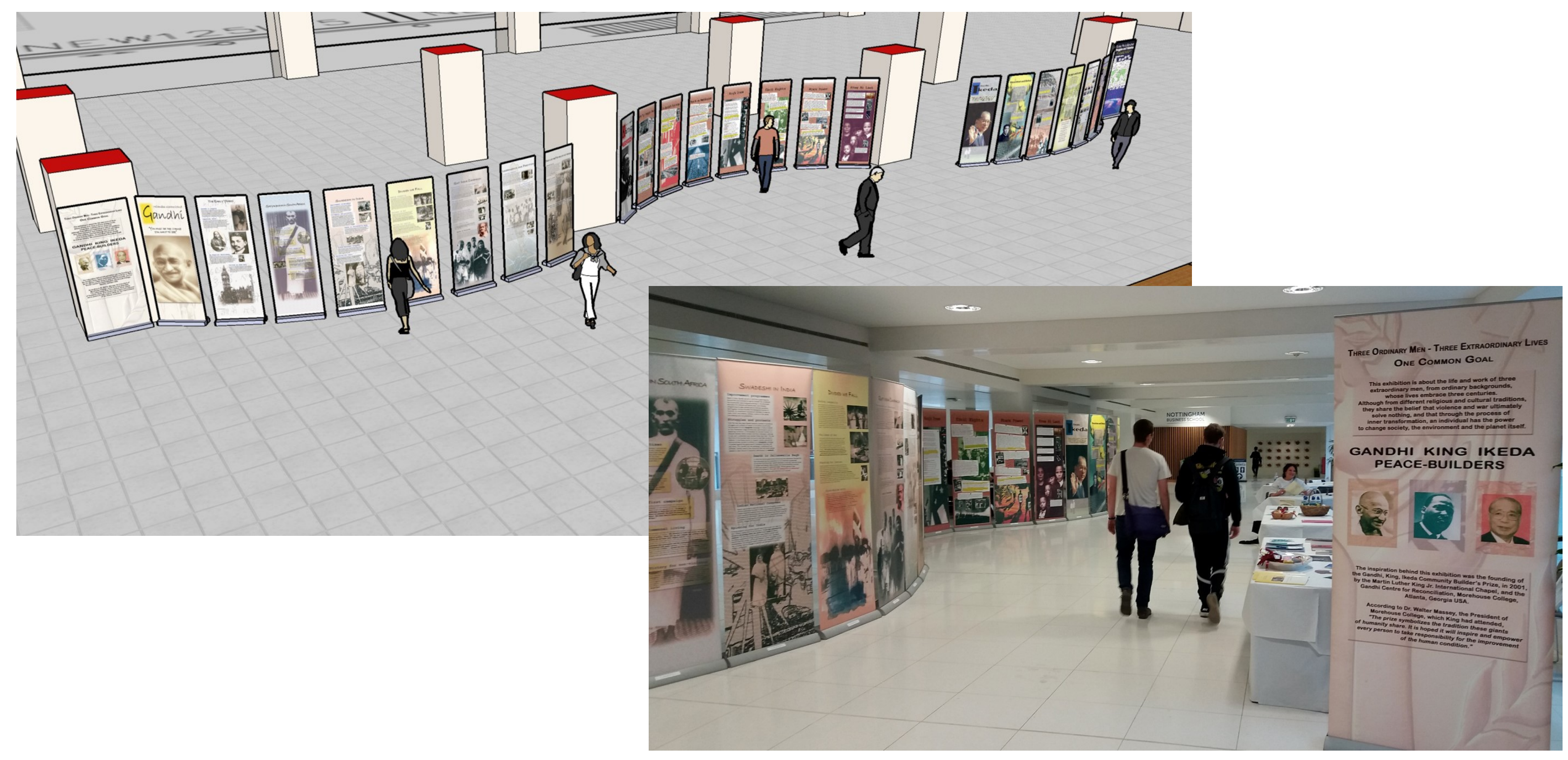

Design and realisation of GKI Exhibition in Newton Building Forum Level 1 Nottingham Trent University, 2-5 May 2017 


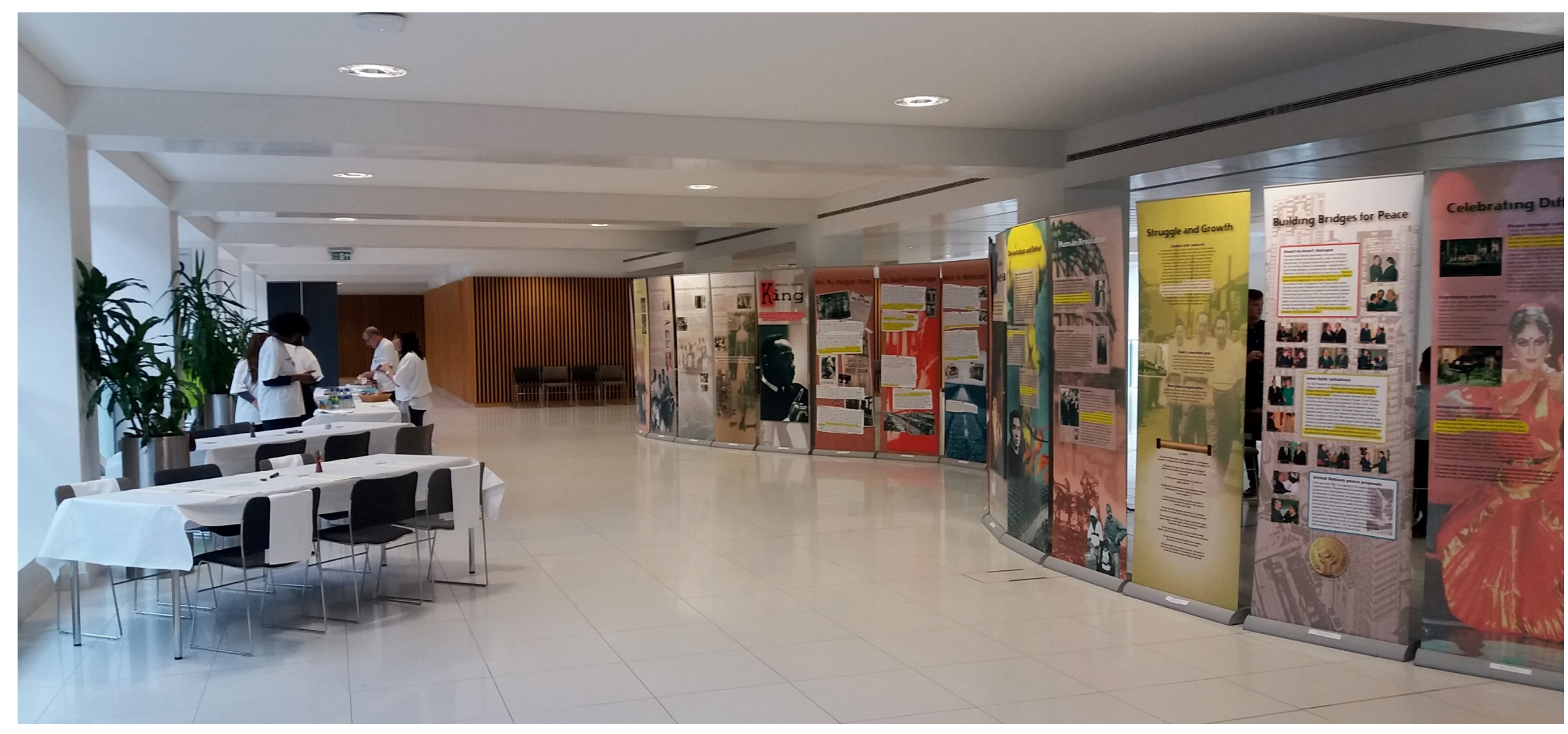

Realisation of GKI Exhibition in Newton Building Forum Level 1 


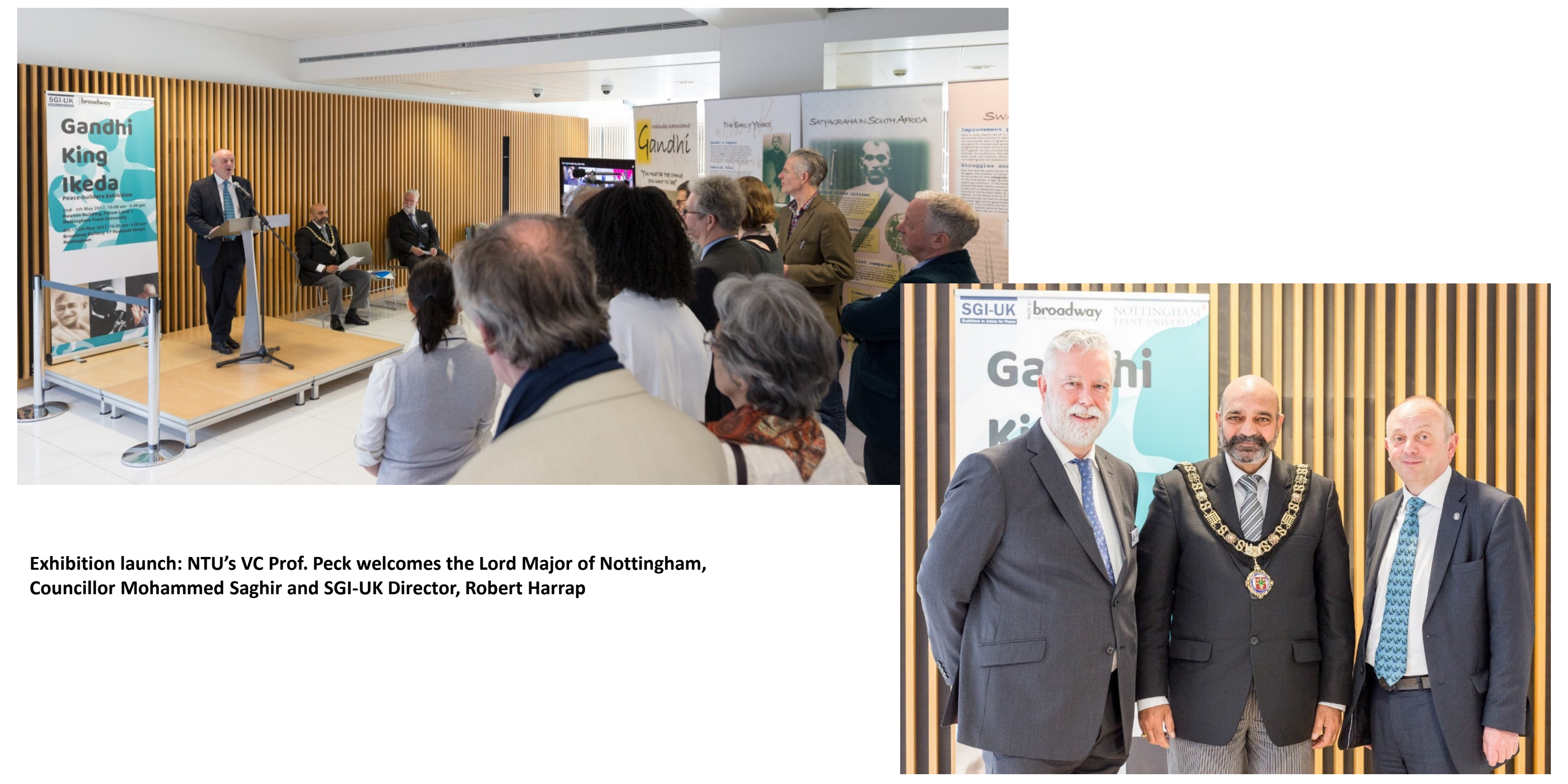




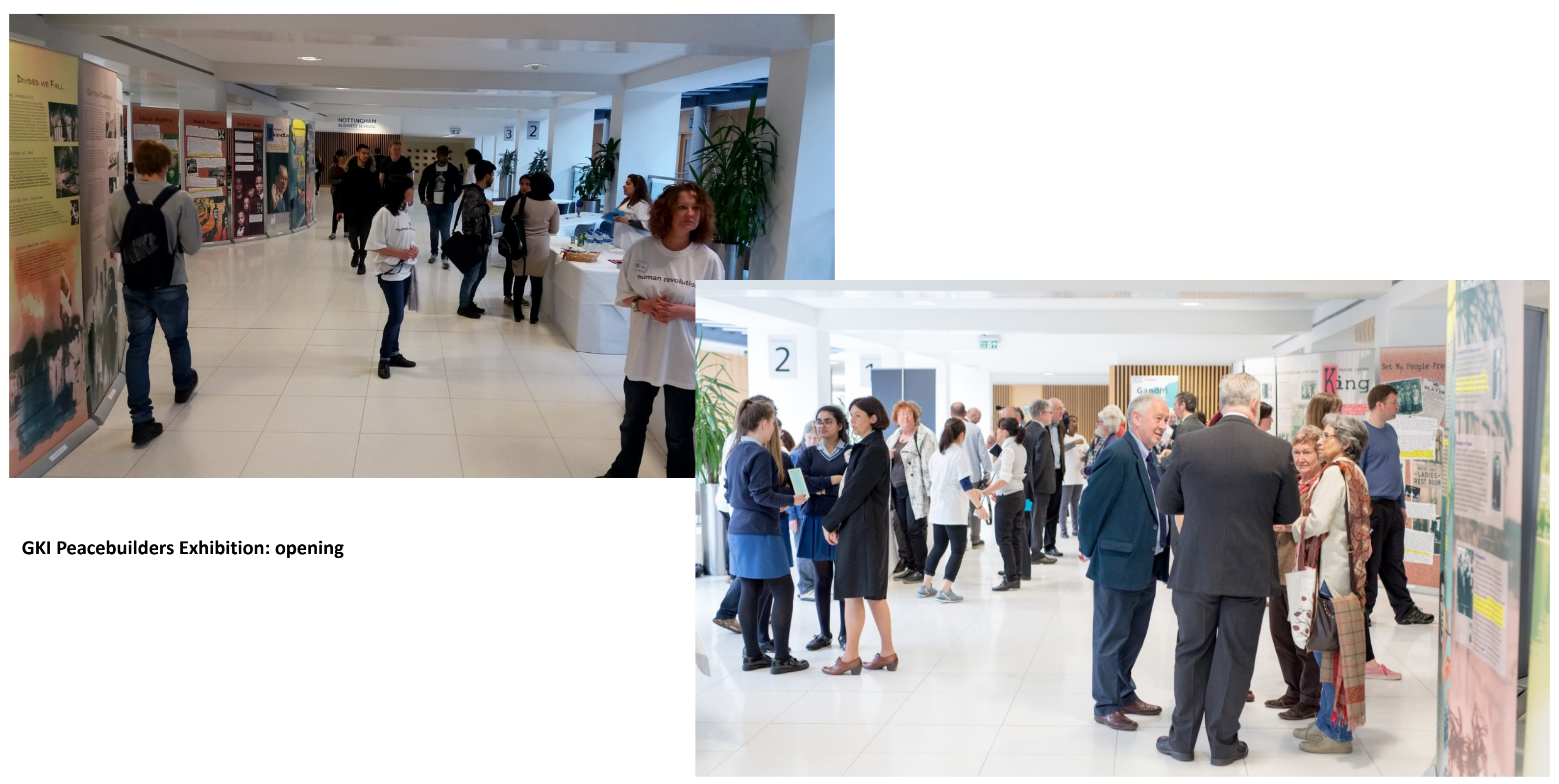


(Chooses ONE of the following)

What is your favourite sound?

What made you last smile?

Shut your eyes and listen. What do you hear

\section{Dish of the Day}

When did you last shout ? How do you listen to a deaf person?

Are you afraid of silence?

Do you enjoy listening to other people?

Do you ever listen to yourself ?

How do you listen if you disagree?

Has listening changed your life?

What does it feel like to not be listened to ?

\section{Thought for the Day}

Pick a card

\section{Dessert}

What are your dreams for the future? What is the most beautiful thing you have ever heard?

CHEF'S SPECIALITY OF THE HOUSE

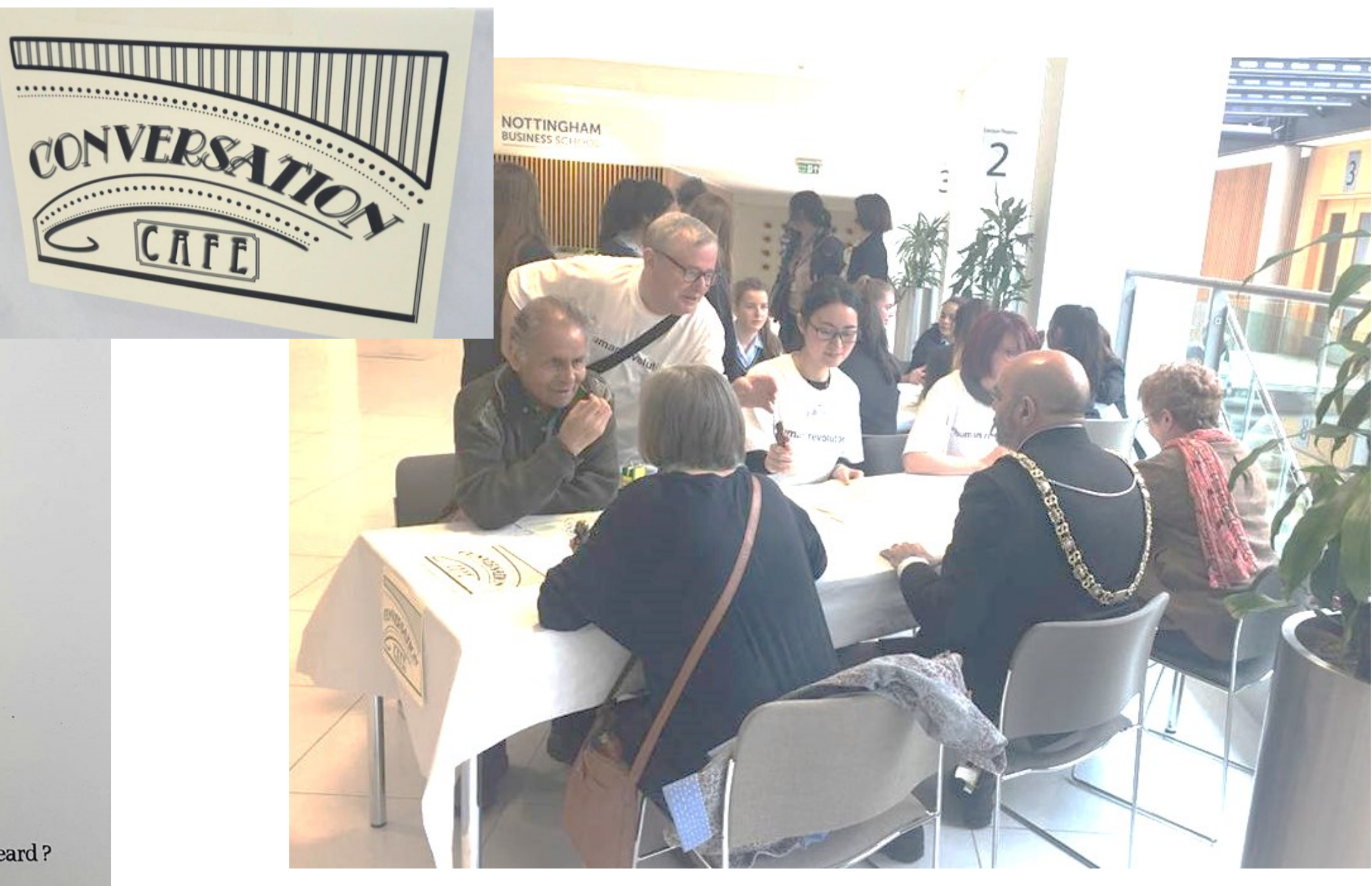

GKI Peacebuilders Exhibition: The Conversation Café' and Food for Thought Menu 


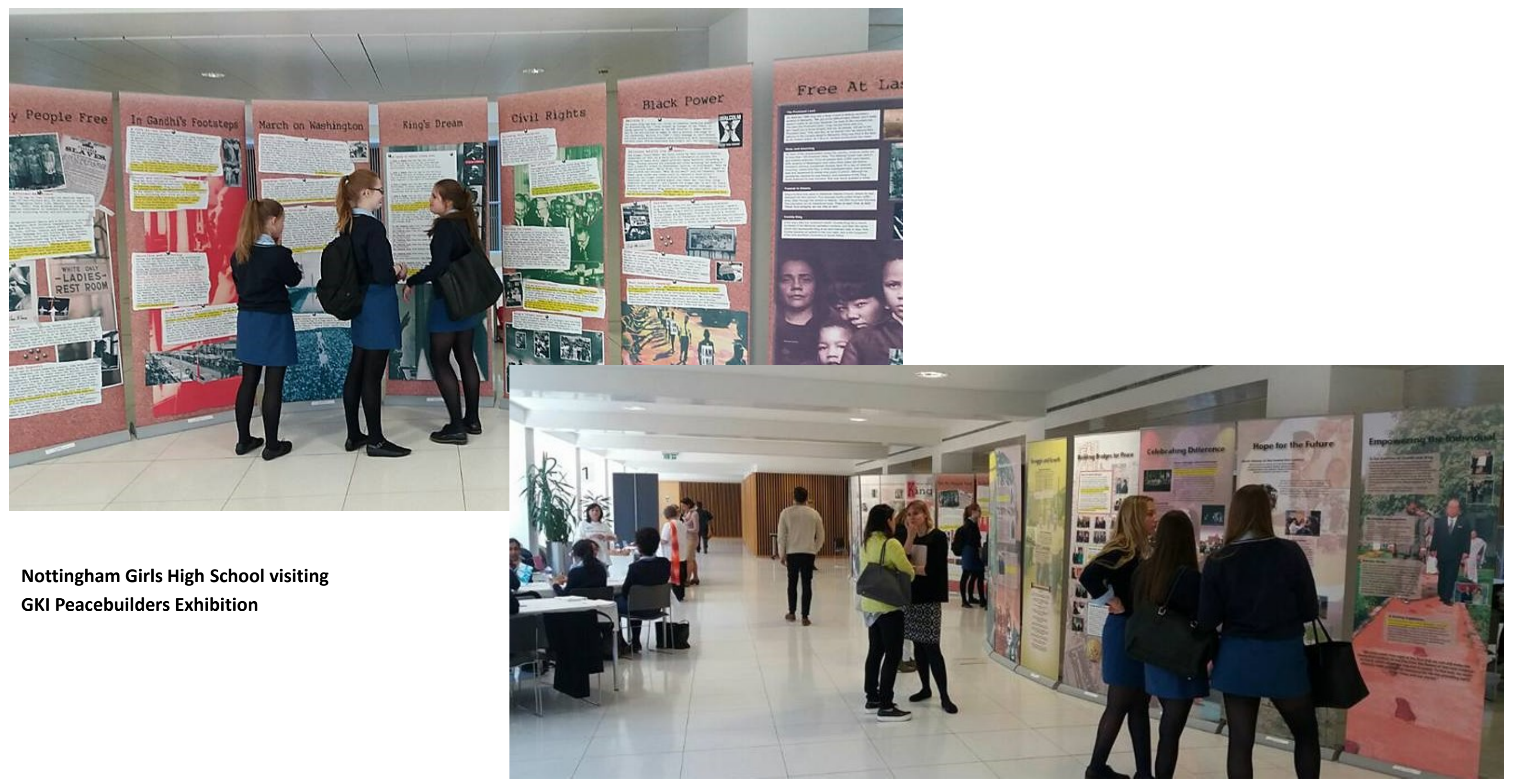


GKI Exhibition in Broadway Cinema Gallery, Nottingham; 6-12 May 2017 


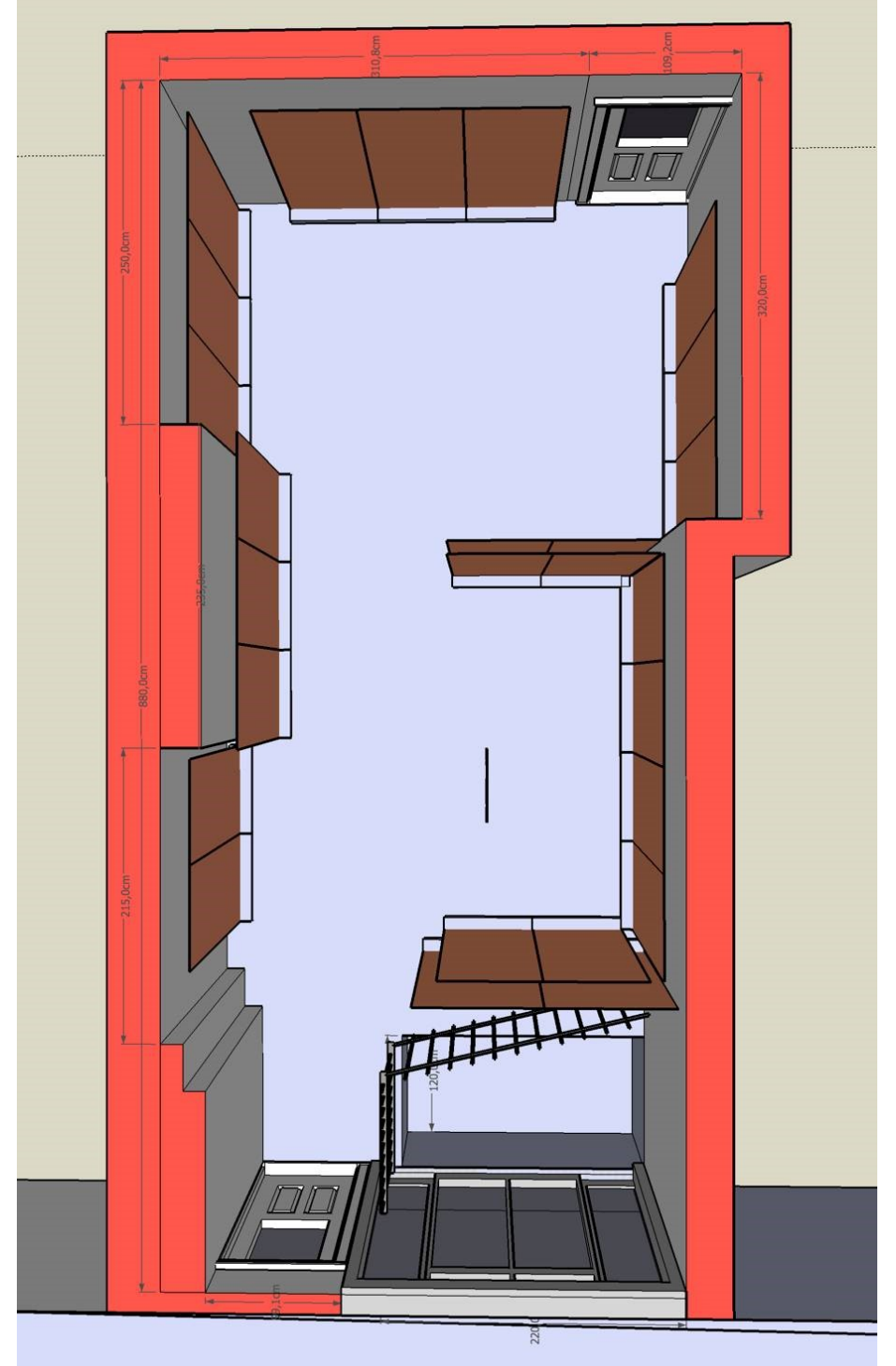

Andrea Moneta Output \#3

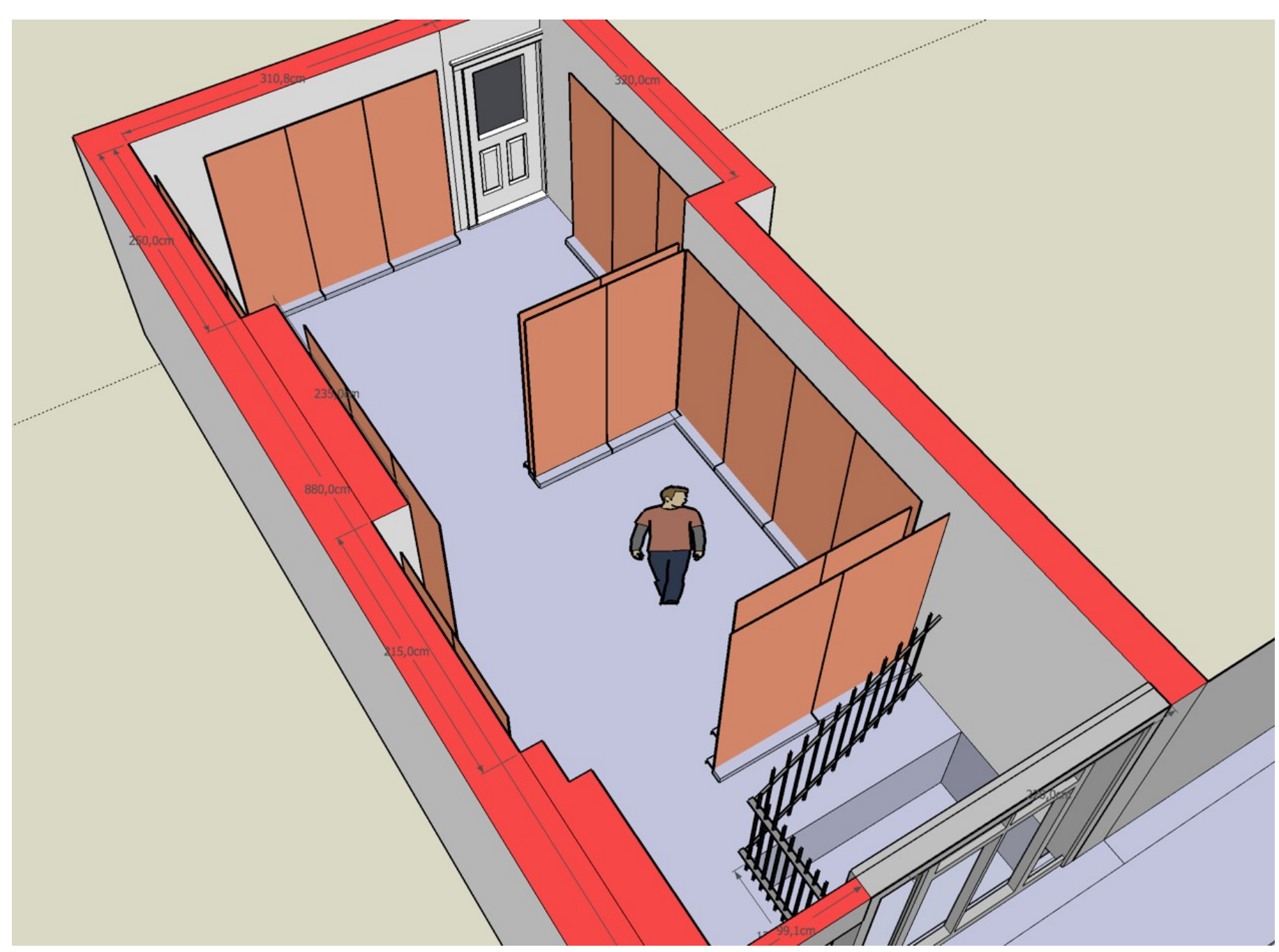

Design of GKI Exhibition in Broadway Cinema Gallery 


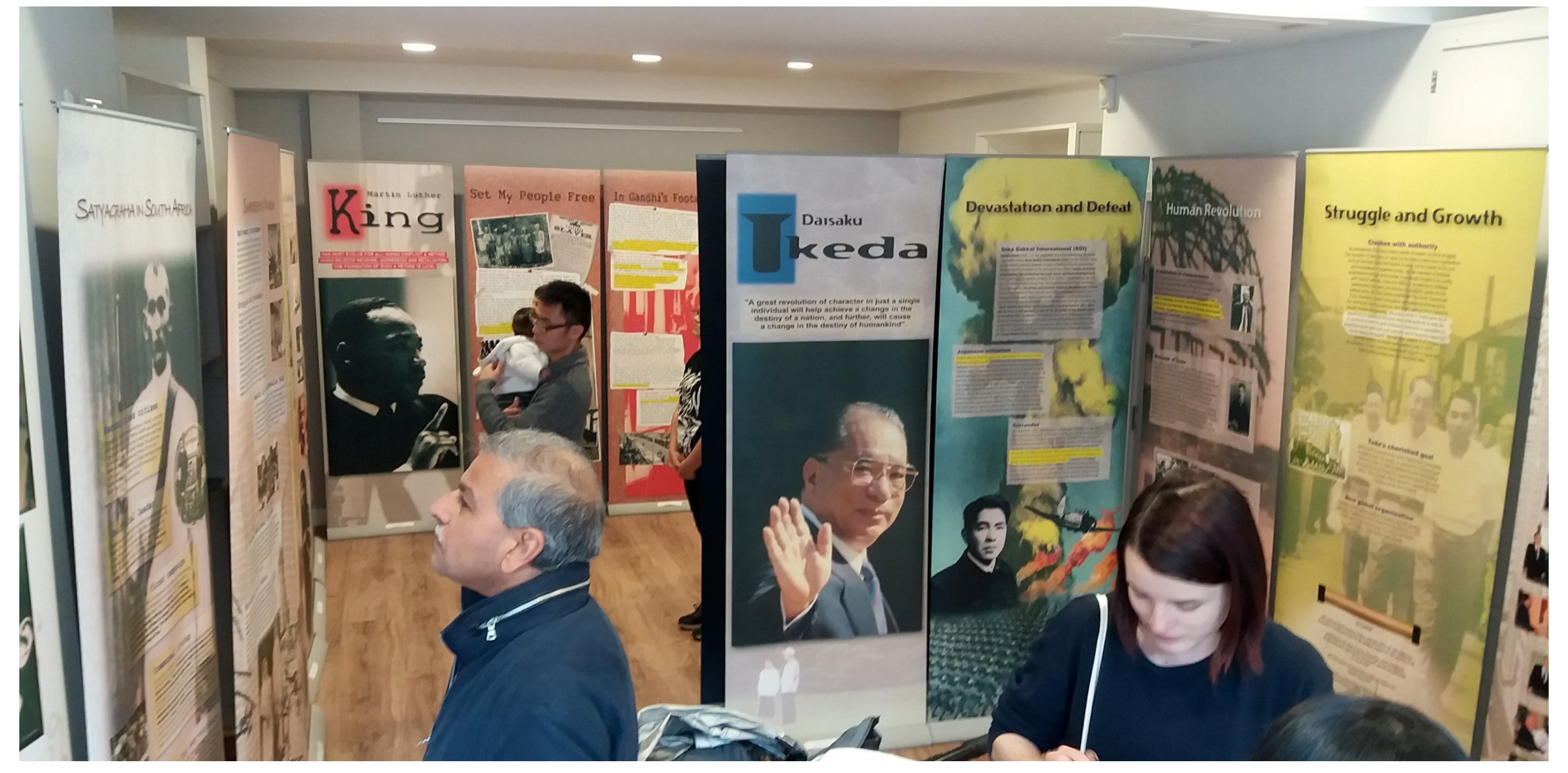

Realisation of GKI Exhibition in Broadway Cinema Gallery, 6-12 May 2017 


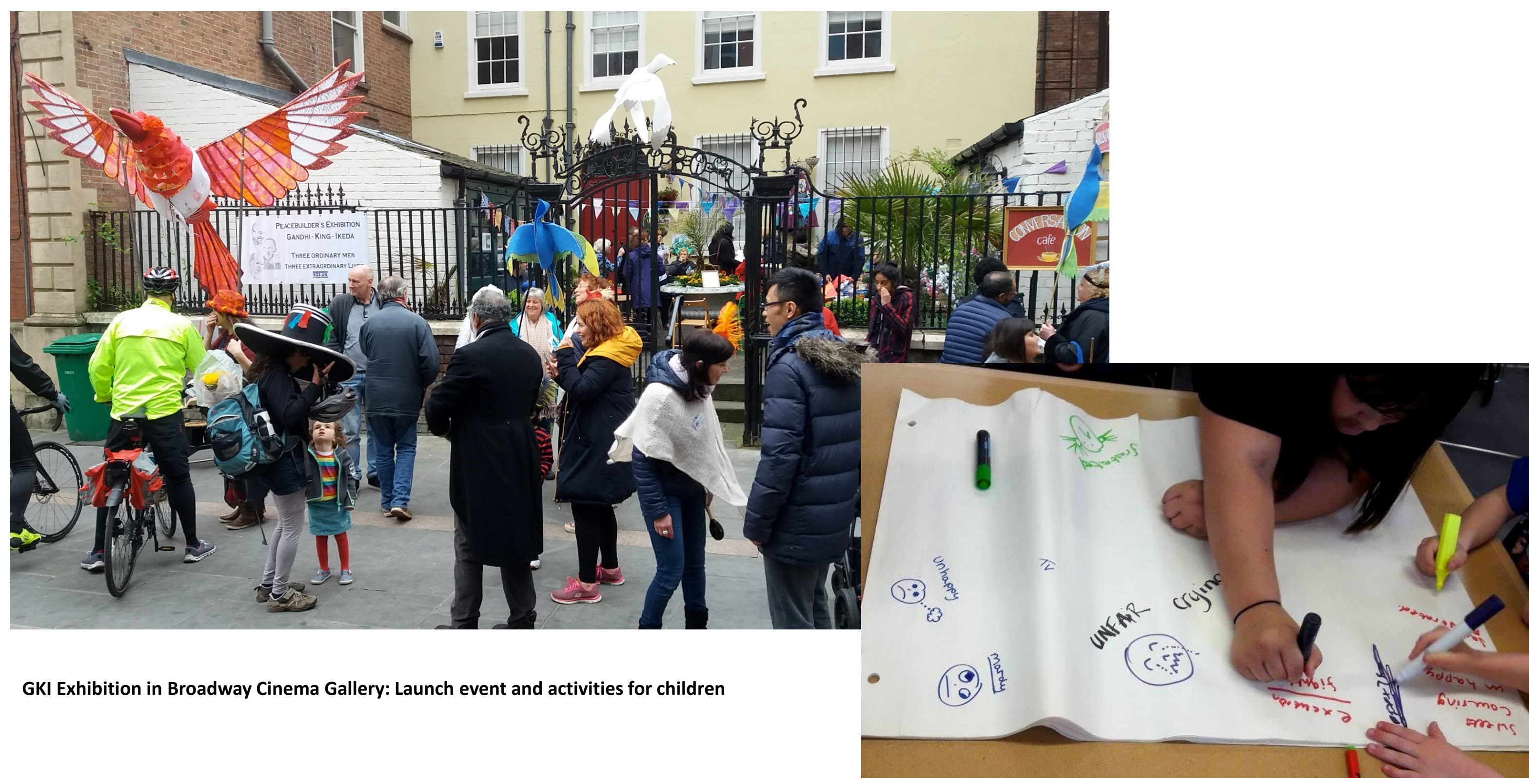



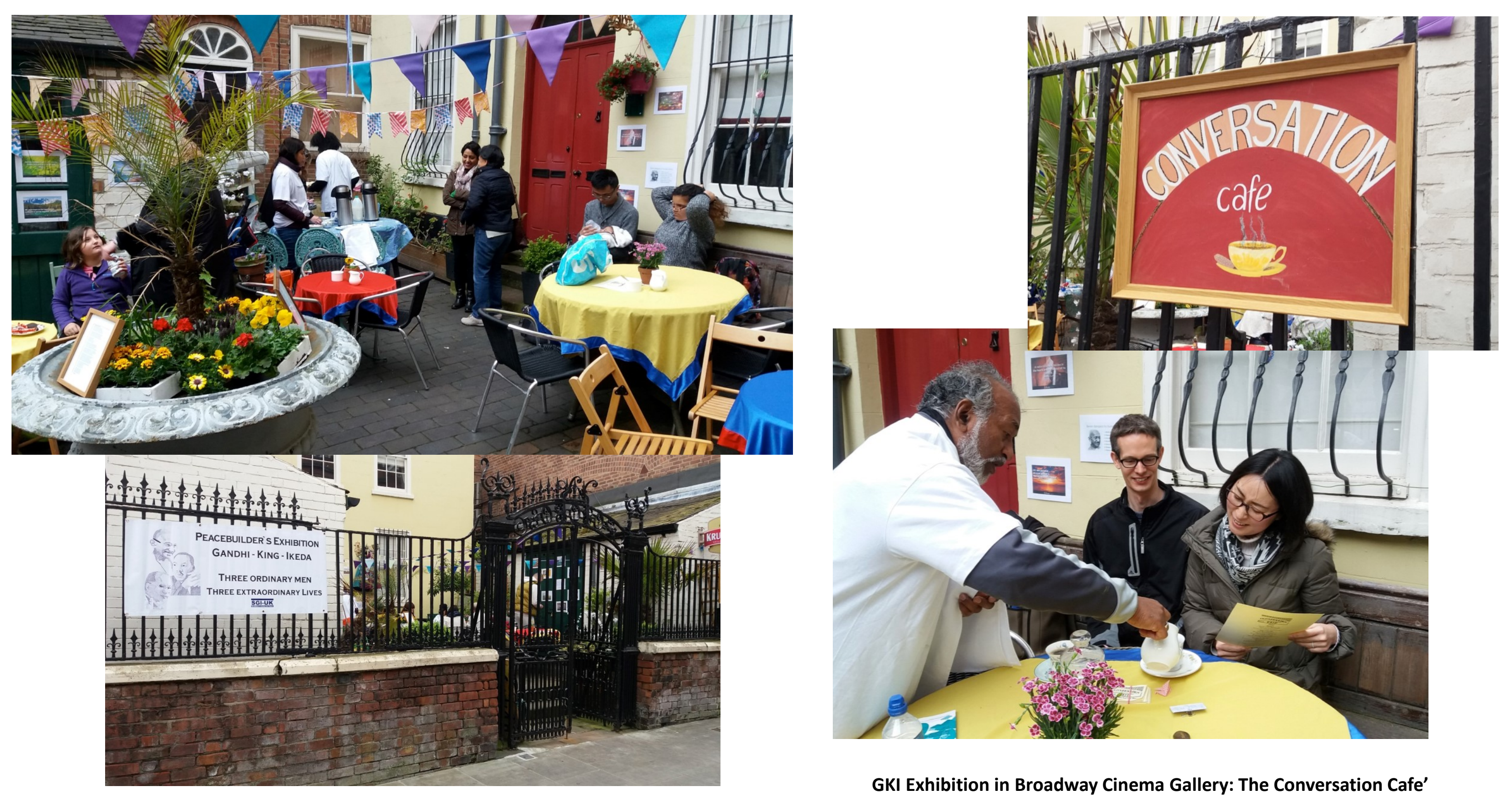
Andrea Moneta

Output Number 3: Gandhi King Ikeda - Peacebuilders Exhibition

Portfolio part 2: Supplementary material 


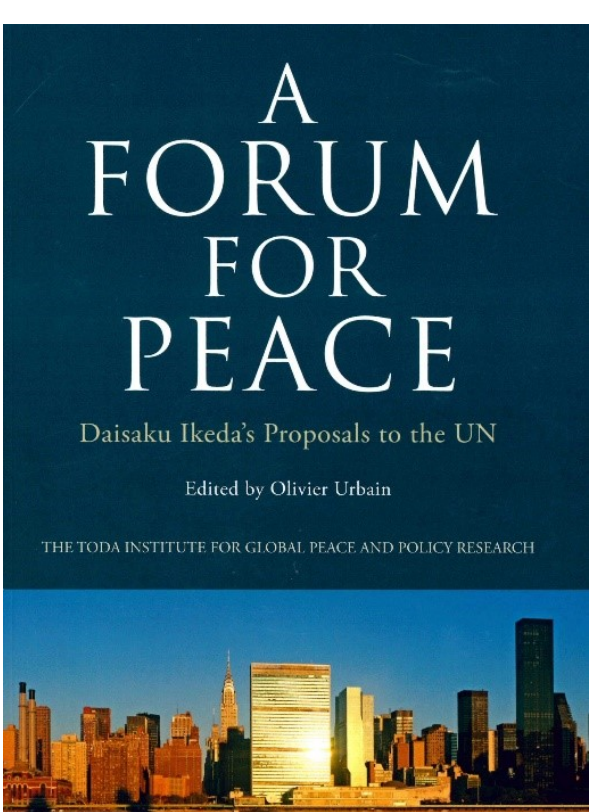

CHOOSE PEACE
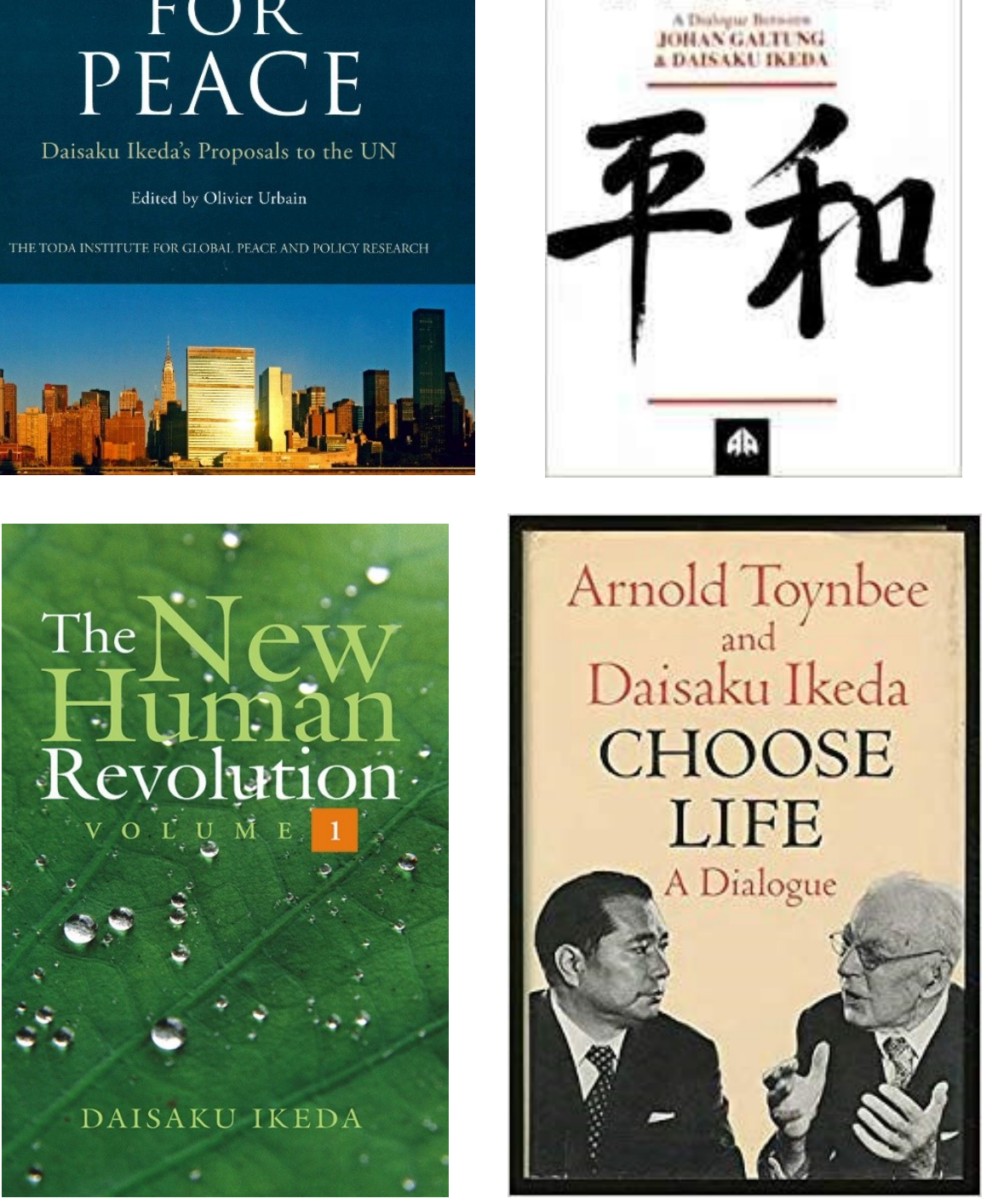
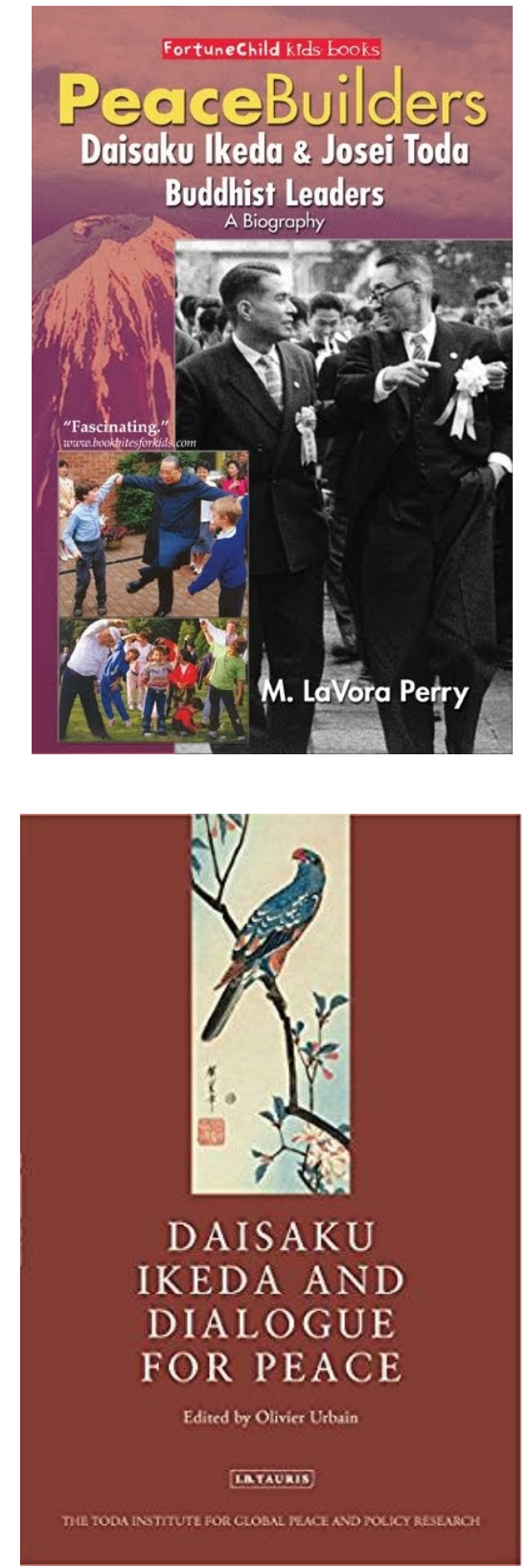

The GKI Exhibition and its related activites had been inspired by Daisaku Ikeda's longstanding commitment for peace; a Japanese Buddhist philosopher, educator, author, he had published more than 50 dialogues with scholars, peace activists and leading world figures; Since 1983, Ikeda has submitted annual peace proposals to the United Nations.

The GKI Exhibition realised an environment to embrace each single visitor and to foster Dialogues for Peace: 'Everything begins with dialogue. Dialogue is the initial step in the creation of value. Dialogue is the starting point and unifying force in all human relationships'. (D. Ikeda)

Daisaku Ikeda's Dialogues for Peace 
Further Output: Graphic Design of pop-up banners and on-screen info had been designed by Moneta.

Exhibition's outcomes were aimed at enhancing the understanding and involvement through 1:1 dialogue of NTU students, High School students, staff and general public in the following key themes:

- HUMANITY AT THE HEART explores their common belief in the innate dignity of humanity.

- PRINCIPLES INTO ACTION illustrates how each man was able to translate his principles into dynamic action.

- NONVIOLENCE explores the principles of nonviolent action as a way of life and a means to bring about positive change in society.

- ADVERSITY AND RESISTANCE shows each man's ability not only to triumph over adversity, but to utilize it to further their growth as humanists.

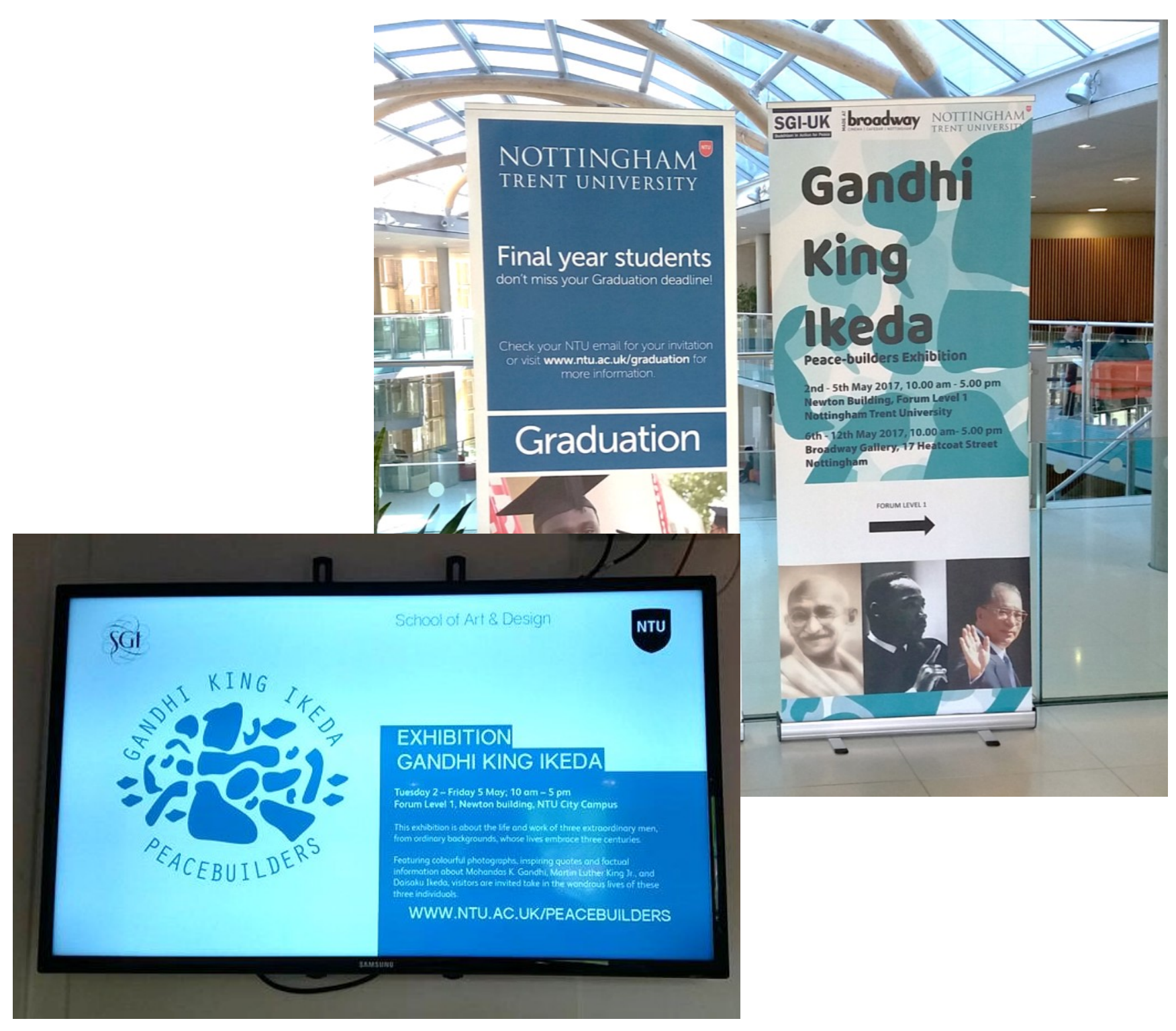

Further Output: Graphic Design of pop-up banners and on-screen info 


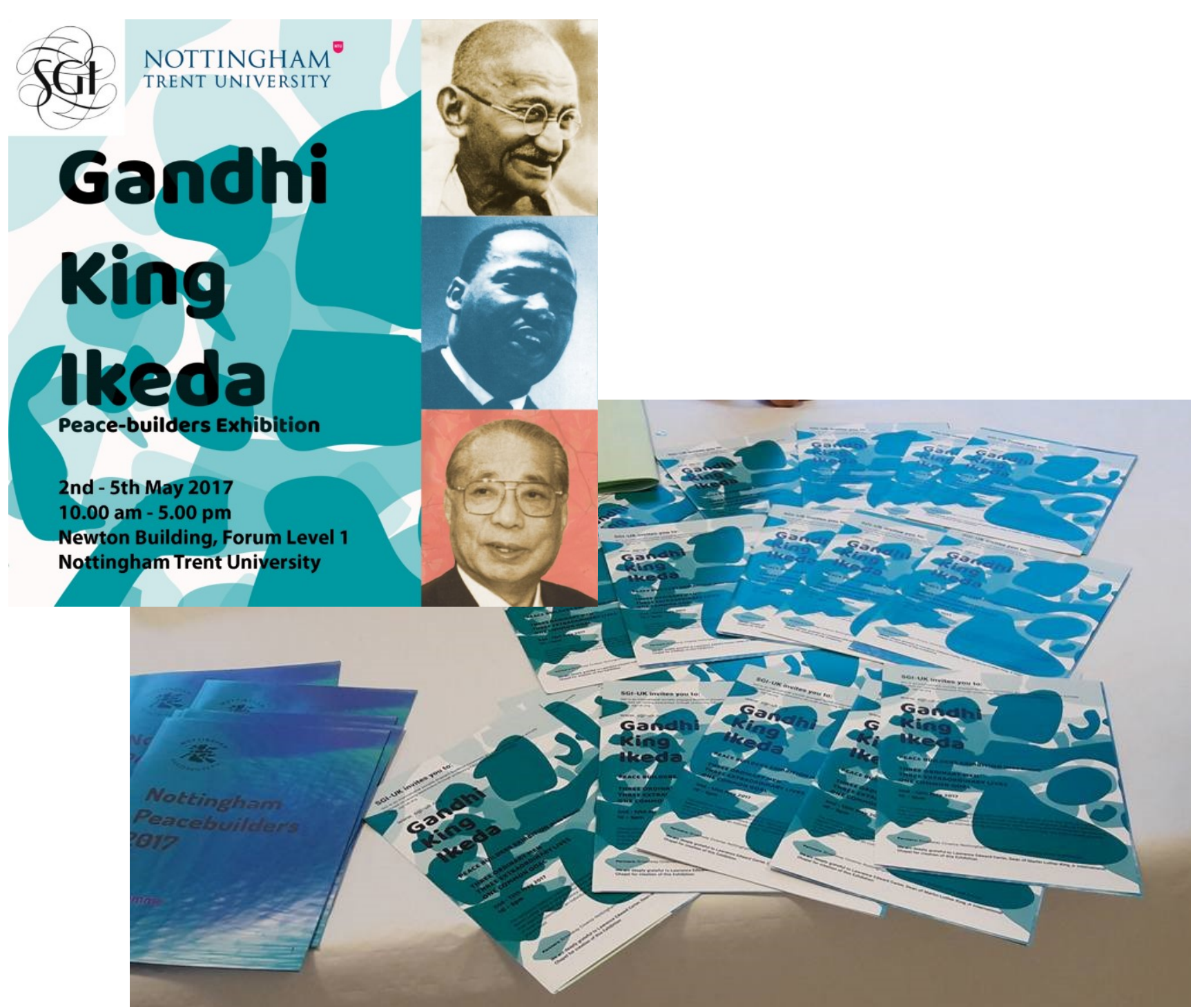

Further Output: Graphic Design of leaflet

\section{GKI Exhibition checked numbers:}

Visitors: 1856 people;

3 visiting School Party: total 132 students; Attending Conversation Cafe': 293 people;

The GKI Exhibition was the core event of Peacebuilders, a programme of events and activities in and around Nottingham from 22nd April to 21st May 2017, supported by:

Arts Council England and Nottingham City Council Arts, City Arts, Journey to Justice Midland3Cities, Broadway Media Centre, Interfaith, Meeting Ground Theatre Company, Malt Cross Café, NUAST and local schools.

Further Output: Graphic Design of leaflet Had been designed by Moneta. 


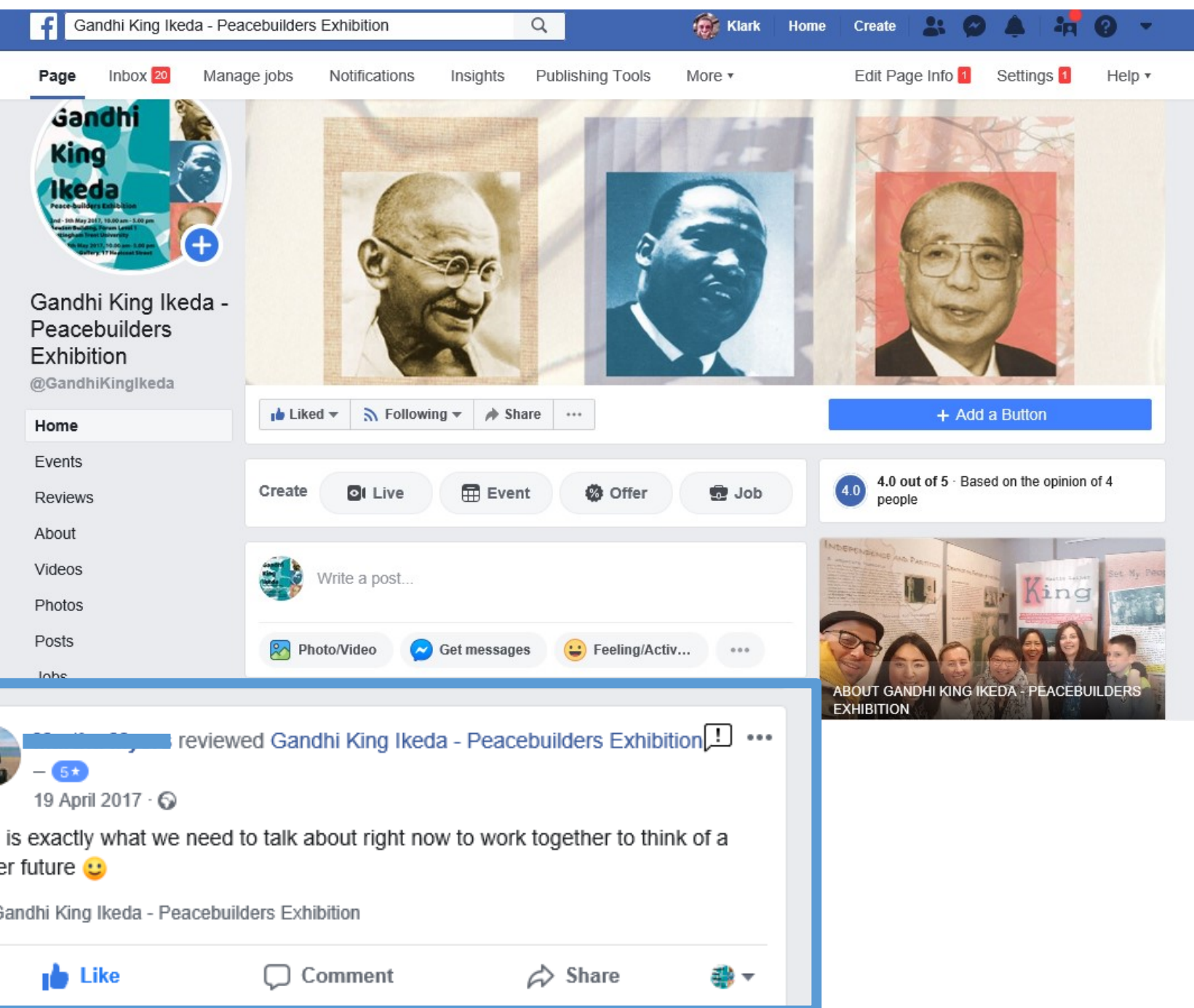

Further Output: Facebook dedicated GKI Exhibition page

\section{GKI Exhibition Web/social network}

GKI Exhibition Facebook page:

https://www.facebook.com/GandhiKinglkeda/

NTU website: https://www.ntu.ac.uk/aboutus/events/events/2017/05/exhibition-gandhiking-ikeda

Peacebuilders Facebook page:

https://www.facebook.com/PeacebuildersUK/

Peacebuilders events

https://www.visit-nottinghamshire.co.uk/whatson/nottingham-peacebuilders-2017-p713221

Further Output: Facebook dedicated GKI Exhibition page built and managed by Moneta, received 2,300 clicks, 280 likes, 183 followers. 


\section{e-bulletin \\ SGI-UK \\ SGI-UK online news bulletin Issue $191 \quad 24.05 .2017$}

SGHUK online news bulletin

Issue $191 \quad 24.05 .2017$

Page 2

\section{Gandhi, King, Ikeda - Peacebuilders Exhibition in the}

\section{East Midlands}

Kosen-rufu was in full bloom in East Lord Mayor of Nottingham Mohammed Refugee Forum, we ensured fellow

Midlands Headquarters throughout Saghir NTU Vicechancellor Edward

Month of May, writes Tanya Myers. Peck and SGI-UK General Director

Members from Lincolnshire,

Derbyshire, Leicestershire and

Gandhi, King, Ikeda Peacebuilders

Gandhi, King, lkeda Peacebuilders

Exhibition and 'Conversation Café'

Et Nottingham Trent University on

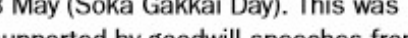

of Nottingham met SGI-UK and

Robert Harrap. Interfaith and schoo

parties partook of our the café 's

President Ikeda. Through heart

heart dialogues these meetings will

continue to resonate far and wide.

In week two, the GKl exhibition was We are so grateful to everyone

moved to the heart of Nottingham's for creating such a passionte and

cultura querter - Brodway Gallery. hertwarming activity. The seeds of

Here, supported by Peacebuilders unity and hope are sown deep and

cultural events across the city and will continue to bloom for the fund

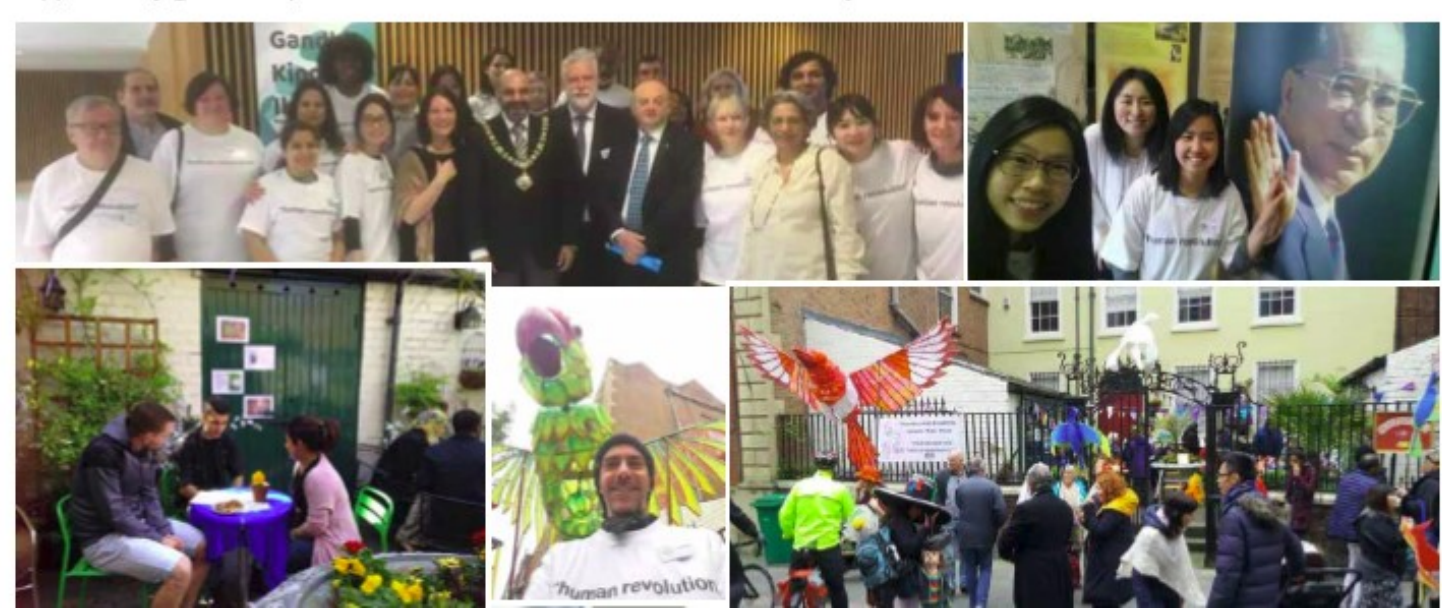

\section{GKI Exhibition press coverage}

The GKI Exhibition was covered by internal NTU press, Nottingham City Council

WhatsOn web page, Visit Nottinghamshire Web page, Notts TV and SGI-UK e-bulletin.

Further Output: Article on SGI-UK e-bulletin, Issue 191, 24 May 2017 